\title{
PROCESSO SAÚDE-DOENÇA NA REGIÃO AMAZÔNICA: FATORES AMBIENTAIS E O SURGIMENTO DE DOENÇAS
}

\section{ARTIGO DE REVISÃo}

CUSTÓDIO, Wenderson Picanço ${ }^{1}$, CHAVES, Juliana Vitória Rocha Leite ${ }^{2}$, PANTOJA, Patrícia Trindade 3 , CÁRDENAS, Anneli Mercedes Celis de ${ }^{4}$, ANDRADE, Rosemary Ferreira de ${ }^{5}$, DAPUREZA, Demilto Yamaguchi ${ }^{6}$, FECURY, Amanda Alves ${ }^{7}$

\section{CUSTÓDIO, Wenderson Picanço. Et al. Processo saúde-doença na região}

Amazônica: fatores ambientais e o surgimento de doenças. Revista Científica Multidisciplinar Núcleo do Conhecimento. Ano. 06, Ed. 12, Vol. 03, pp. 05-21. Dezembro de 2021. ISSN: 2448-0959, Link de acesso: https://www.nucleodoconhecimento.com.br/saude/surgimento-de-doencas, DOI: 10.32749/nucleodoconhecimento.com.br/saude/surgimento-de-doencas

\footnotetext{
${ }^{1}$ Mestrando em Ciências da Saúde pela Universidade Federal do Amapá; Especialista em Hematologia pela União Brasileira de Faculdades; Graduado em Bacharelado em Biomedicina pela Faculdade de Macapá; Graduado em Licenciatura em Pedagogia pela Universidade Cidade de São Paulo; Graduando em Licenciatura em Ciências Biológicas Universidade Cidade de São Paulo. ORCID: 0000-0003-0424-6852.

${ }^{2}$ Mestranda em Ciências da Saúde pela Universidade Federal do Amapá; Pós-Graduanda em Odontopediatria pelo Grupo de Especialidades Odontológicas; Pós-Graduação em Odontologia para o paciente oncológico pelo Hospital Sírio Libanês; Graduação em Odontologia pela Faculdade de Macapá - FAMA. ORCID: 0000-00027595-9094.

${ }^{3}$ Mestranda em Ciências da Saúde pela Universidade Federal do Amapá; Pós-Graduação em Urgência e Emergência e UTI pela Faculdade Madre Tereza-FAMAT; Pós-Graduação em Docência e Gestão do Nível Superior pela Faculdade Fatec; Graduação em Enfermagem pela Faculdade de Macapá - FAMA. ORCID: 00000002-8667-0165

${ }^{4}$ Doutora em Enfermagem pela Escola de Enfermagem da Universidade de São Paulo EEUSP, Mestre em Enfermagem Fundamental pela Universidade de São Paulo EEUSP. Graduação em Enfermagem pela Universidade Nacional do Callao em Lima Perú. ORCID: https://orcid.org/0000-0002-6581-4326.

${ }^{5}$ Graduada em Enfermagem e Obstetrícia pela Universidade do Estado do Pará (UEPA), Mestre em Enfermagem (UFPA) e Doutora em Ciência: desenvolvimento socioambiental (NAEA/UFPA). Atualmente é professor Titular da Universidade Federal do Amapá. Desenvolve trabalhos nos seguintes temas: saúde pública, epidemiologia, amapá, Amazônia, malária e migração. ORCID: https://orcid.org/0000-0003-4472-8565.

${ }^{6}$ Doutor em Ciências, Mestre em Educação Física e Graduado em Educação Física. ORCID: https://orcid.org/0000-0001-8336-2178.

${ }^{7}$ Doutorado e mestrado em Doenças Tropicais, Especialista em Microbiologia, biomédica ORCID: http://orcid.org/0000-0001-5128-8903.
}

RC: 102839

Disponível em: https://www.nucleodoconhecimento.com.br/saude/surgimento-dedoencas 


\section{RESUMO}

Introdução: A Amazônia sempre foi objeto de inúmeros estudos com foco em seu meio ambiente, sociedade e saúde. Questão Norteadora: Quais fatores ambientais contribuem para o surgimento de doenças na região amazônica? Objetivo: Abordar os principais fatores ambientais que contribuem para o surgimento de doenças na região amazônica. Método: Trata-se de uma revisão da literatura nas bases de dados Scientific Electronic Library Online (SciELO), US National Library of Medicine National Institutes of Health (PubMeD), Biblioteca Virtual em Saúde (BVS) e Instituto Nacional de Pesquisas Espaciais (INPE). Ao todo foram utilizados 18 artigos na construção do estudo, todos passando pelos critérios de inclusão e de exclusão estabelecidos com 0 intuito de filtrar somente periódicos com abordagens da temática. Resultados: Do ponto de vista epidemiológico, o espaço amazônico formado pela interação do sistema socioecológico apresenta características diferentes de outras partes do país. Essa diferença é causada pelo fundamento ecológico natural e suas formas de ocupação e desenvolvimento. Conclusão: Os principais fatores ambientais que contribuem para o surgimento de doenças na região amazônica são o desmatamento, queimadas, poluição dos rios, processo de urbanização e agronegócio.

Palavras-chave: Saúde-doença, Amazônia, Fatores ambientais.

\section{INTRODUÇÃO}

A Amazônia sempre foi objeto de inúmeros estudos com foco em seu meio ambiente, sociedade e desenvolvimento. Publicações nas últimas décadas discutiram aspectos regionais importantes, tais como biodiversidade, usos das terras, da ciência e tecnologia, crescimento urbano (BROWDER e GODFREY, 2017), desenvolvimento sustentável e projetos de desenvolvimento causadores de desmatamento (PERZ, 2002). 
Para entender a complexidade da Amazônia em relação às diferentes regiões do mundo, é importante lembrar que essa complexidade não se limita às suas características biológicas e ambientais, mas está relacionada à forma como a população que a habita difere em seu modo de vida e na maneira de agir e pensar (ROLIM, 2015).

O conceito de saúde-doença pode assumir uma dimensão regional, já que nesta região existe um imenso vazio de informações científicas sobre as condições socioambientais, para atender às demandas da sociedade. Cabe destacar que nesta região tem-se alta concentração de pessoas fixadas nos centros urbanos, com destaque nas capitais, causando problemas generalizados nos grandes centros como: falta de água tratada e saneamento básico, proliferação de insetos vetores de doenças, notadamente anofelinos transmissores de malária, dengue entre outros (CAÑETE e RAVENA-CAÑETE, 2010).

A escolha desta região como objeto de análise justifica-se por suas especificidades ambientais (clima, ecossistemas e biodiversidade) e demográficas (diversidade social com baixa densidade populacional e concentração em cidades), que, em combinação com processos econômicos como a agricultura extensiva, a pecuária, a exploração mineral, a hidroeletricidade e a indústria impactam a saúde da população em função de seu modelo de desenvolvimento. A partir disso a questão norteadora do estudo é: quais fatores ambientais contribuem para o surgimento de doenças na região amazônica?

Dessa forma, o objetivo desse estudo foi destacar os fatores ambientais que contribuem para o surgimento de doenças na região da amazônica assim como, dar ênfase a pesquisas direcionadas à região, possibilitando um maior acervo bibliográfico sobre a temática, além de destacar a necessidade de criação e reformulação de políticas públicas de saúde para a população que reside nesta região. 


\section{METODOLOGIA}

Este trabalho foi realizado por meio de revisão de literatura em periódicos científicos, disponíveis nos sites e bancos de dados: Scielo, pubmed, Biblioteca Virtual em Saúde e estudos realizados Instituto Nacional de Pesquisas Espaciais. A pesquisa dos artigos ocorreu entre agosto a novembro de 2021, e foram coletados 18 artigos e todos eles selecionados para a construção do estudo. Os critérios de inclusão foram artigos publicados no período de 2000 a 2021, nos idiomas inglês, espanhol e português. Já os critérios de exclusão foram artigos publicados anteriores ao ano 2000, duplicados, editoriais de carta do editor, bem como periódicos em idiomas diferentes dos citados nos critérios de inclusão. Os descritores utilizados para a busca dos estudos foram: Saúde-doença; Amazônia; Fatores ambientais.

Assim, este artigo é uma análise do processo saúde-doença na região Amazônica e os fatores ambientes que influenciam no surgimento de doenças (fatores sociais, econômicos, culturais e ambientais, e outros fatores que afetam a ocorrência de problemas de saúde na população), Segundo Sobral e Freitas (2010) utilizando variáveis quantificáveis (indicadores) e revisão da literatura.

\section{RESULTADOS}

Tabela 1. Principais Resultados dos Artigos Selecionados para Pesquisa

\begin{tabular}{|c|c|c|c|}
\hline & Título & $\begin{array}{l}\text { Autores, ano } \\
\text { de } \\
\text { publicação e } \\
\text { país }\end{array}$ & Principais resultados \\
\hline $\begin{array}{l}\text { ARTIGO } \\
\text { I }\end{array}$ & $\begin{array}{l}\text { A evolução do } \\
\text { conhecimento sobre } \\
\text { hepatites virais na } \\
\text { região Amazônica: da } \\
\text { epidemiologia e e }\end{array}$ & $\begin{array}{l}\text { Bensabath e } \\
\text { Soares, } \\
\text { 2016, Brasil. }\end{array}$ & $\begin{array}{l}\text { O estudo busca demonstrar } \\
\text { uma doença similar a febre } \\
\text { amarela, porém considerada } \\
\text { como nova doença, ocorre em } \\
\text { áreas dos vales dos Rios Juruá, }\end{array}$ \\
\hline
\end{tabular}


etiologia à prevenção.

II

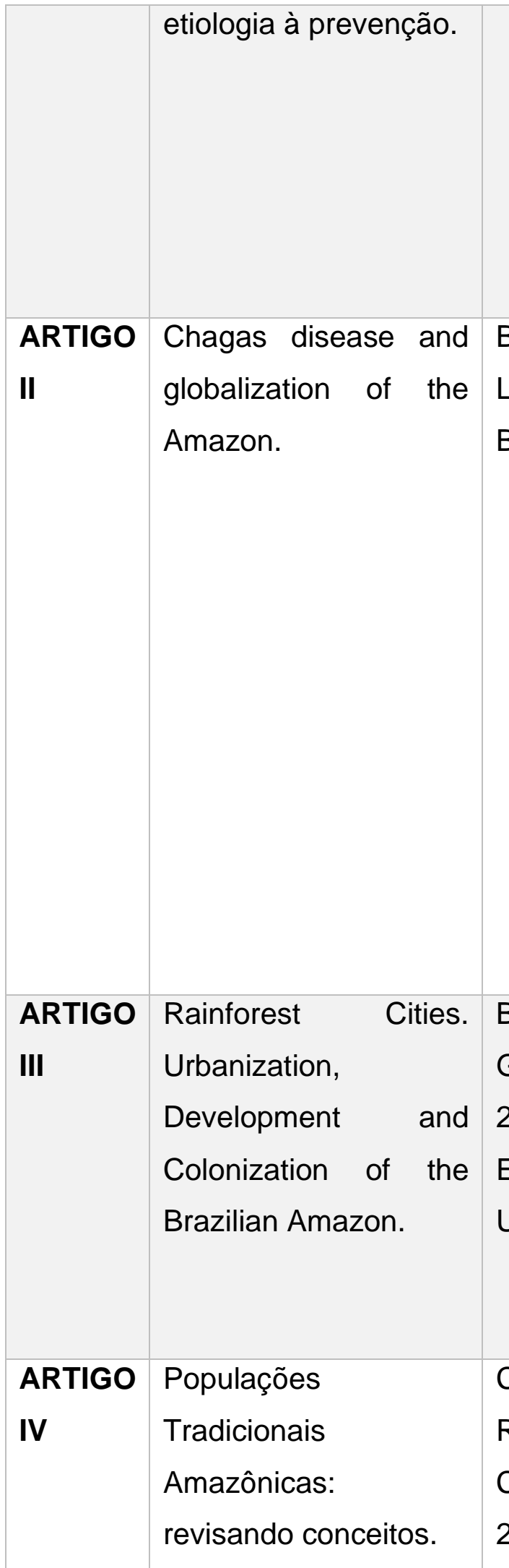

Purus e Madeira. Temida pelos residentes pela alta letalidade, sendo clinicamente uma hepato-encefalopatia de evolução fulminante (média de 5 a 6 dias).

$O$ artigo em questão levanta Léon, 2007, aumento do número de casos Brasil. autóctones da doença de Chagas na Amazônia desde a década de 1970 leva ao temor de que a doença se transforme em um novo problema de saúde pública na região. Essa transformação no padrão epidemiológico da doença na Amazônia pode ser explicada pelas mudanças ambientais $\mathrm{e}$ sociais dos últimos 30 anos.

Browder e $\mathrm{O}$ estudo demonstrou a
Godfrey, conciliação das questões ambientais diante da atual urbanização global considerando a intensa transição urbana em curso na região Amazônica.

Cañete e $\mathrm{O}$ trabalho objetivou discutir de Ravena- forma crítica o conceito de Cañete, população tradicional dentro do 2010, Brasil. contexto amazônico, verificando 


\begin{tabular}{|c|c|c|c|}
\hline & & & $\begin{array}{l}\text { que o conceito de população } \\
\text { tradicional, entendido como } \\
\text { uma identidade coletiva que tem } \\
\text { a especificidade de desenvolver } \\
\text { modos de vida de integração e } \\
\text { intimidade com o meio } \\
\text { ambiente. }\end{array}$ \\
\hline $\begin{array}{l}\text { ARTIGO } \\
\text { v }\end{array}$ & $\begin{array}{l}\text { O trabalho como } \\
\text { determinante do } \\
\text { processo saúde- } \\
\text { doença. }\end{array}$ & $\begin{array}{l}\text { Cardoso, } \\
\text { 2015, Brasil. }\end{array}$ & $\begin{array}{l}\text { O estudo analisou como, no } \\
\text { contexto atual, as condições } \\
\text { organizacionais e físicas do } \\
\text { trabalho, as situações e as } \\
\text { relações de trabalho e as } \\
\text { formas de gestão estão } \\
\text { determinando e contribuindo } \\
\text { para o adoecimento dos } \\
\text { trabalhadores para } \\
\text { compreender uma relação tão } \\
\text { complexa }\end{array}$ \\
\hline $\begin{array}{l}\text { ARTIGO } \\
\text { VI }\end{array}$ & $\begin{array}{l}\text { Determinante da } \\
\text { saúde no Brasil: a } \\
\text { procura da equidade } \\
\text { na saúde. }\end{array}$ & $\begin{array}{l}\text { Carrapato et } \\
\text { al., 2017, } \\
\text { Brasil. }\end{array}$ & $\begin{array}{l}\text { O presente estudo teve como } \\
\text { objetivo identificar, por meio da } \\
\text { bibliometria, quais são os } \\
\text { determinantes da saúde de } \\
\text { maior impacto na saúde da } \\
\text { população diante da questão da } \\
\text { qualidade de vida associa-se } \\
\text { quase de forma imediata à } \\
\text { saúde. }\end{array}$ \\
\hline $\begin{array}{l}\text { ARTIGO } \\
\text { VII }\end{array}$ & $\begin{array}{l}\text { The Health of } \\
\text { Indigenous Peoples in } \\
\text { the Brazilian Amazon. }\end{array}$ & $\begin{array}{l}\text { Confalonieri, } \\
2000, \\
\text { Amsterdam. }\end{array}$ & $\begin{array}{l}\text { O artigo procurou demonstrar } \\
\text { as doenças epidêmicas e } \\
\text { destruição ambiental de muitas }\end{array}$ \\
\hline
\end{tabular}




\begin{tabular}{|c|c|c|c|}
\hline & & & $\begin{array}{l}\text { tribos que passaram do contato } \\
\text { ao deslocamento, dizimação e } \\
\text { extinção em uma única } \\
\text { geração, como também, a } \\
\text { desculturação e a construção } \\
\text { de grandes projetos de } \\
\text { desenvolvimento e como } \\
\text { tiveram efeitos catastróficos } \\
\text { sobre as populações nativas da } \\
\text { Amazônia. }\end{array}$ \\
\hline $\begin{array}{l}\text { ARTIGO } \\
\text { VIII }\end{array}$ & $\begin{array}{l}\text { Saúde na Amazônia: } \\
\text { um modelo conceitual } \\
\text { para a análise de } \\
\text { paisagens e doenças. }\end{array}$ & $\begin{array}{l}\text { Confalonieri, } \\
\text { 2005, Brasil. }\end{array}$ & $\begin{array}{l}\text { O estudo fez uma revisão do } \\
\text { perfil epidemiológico das } \\
\text { populações amazônicas em } \\
\text { relação com a dinâmica } \\
\text { socioambiental da região e } \\
\text { desenvolveram um modelo } \\
\text { conceitual de análise que inclui } \\
\text { três grandes categorias de } \\
\text { paisagens na Amazônia: } \\
\text { naturais, antropizadas e } \\
\text { construídas. }\end{array}$ \\
\hline $\begin{array}{l}\text { ARTIGO } \\
\text { IX }\end{array}$ & $\begin{array}{l}\text { Indicadores de } \\
\text { sustentabilidade } \\
\text { ambiental e de saúde } \\
\text { na Amazônia Legal. }\end{array}$ & $\begin{array}{l}\text { Freitas } \\
\text { Giatti, 2009, } \\
\text { Brasil. }\end{array}$ & $\begin{array}{l}\text { O artigo demonstrou os } \\
\text { desafios atuais da Saúde } \\
\text { Pública que está principalmente } \\
\text { em estruturar sistemas de } \\
\text { indicadores que permitam } \\
\text { monitorar as condições e } \\
\text { tendências da sustentabilidade } \\
\text { ambiental e de saúde. O artigo } \\
\text { centrou em mostrar como }\end{array}$ \\
\hline
\end{tabular}




\begin{tabular}{|c|c|c|c|}
\hline & & & $\begin{array}{l}\text { enfrentar esse desafio tendo } \\
\text { como foco de análise os } \\
\text { estados integrantes da } \\
\text { Macrorregião Amazônia Legal. }\end{array}$ \\
\hline $\begin{array}{l}\text { ARTIGO } \\
x\end{array}$ & $\begin{array}{l}\text { Custo das doenças } \\
\text { atribuíveis a fatores } \\
\text { ambientais na cidade } \\
\text { de Manaus, } \\
\text { Amazonas, Brasil. }\end{array}$ & $\begin{array}{l}\text { Medeiros, } \\
\text { 2014, Brasil. }\end{array}$ & $\begin{array}{l}\text { O estudo apresentou a } \\
\text { estimativa do custo das } \\
\text { doenças atribuíveis a fatores } \\
\text { ambientais na cidade de } \\
\text { Manaus, entre os anos de } 1998 \\
\text { a 2009, mostraram as causas } \\
\text { de internação hospitalar e como } \\
\text { elas foram agrupadas com base } \\
\text { nos estudos de Carga Global de } \\
\text { Doença e da Análise } \\
\text { Comparativa de Risco da } \\
\text { Organização Mundial da Saúde. }\end{array}$ \\
\hline $\begin{array}{l}\text { ARTIGO } \\
\text { XI }\end{array}$ & $\begin{array}{l}\text { Recent Progress in } \\
\text { Modeling Biome- } \\
\text { Climate Interactions in } \\
\text { Amazônia. }\end{array}$ & $\begin{array}{l}\text { Nobre, 2004, } \\
\text { Brasil. }\end{array}$ & $\begin{array}{l}\text { A pesquisa buscou investigar a } \\
\text { relação entre o desmatamento } \\
\text { histórico e a precipitação em } \\
\text { diferentes escalas geográficas } \\
\text { no sul da Amazônia brasileira } \\
\text { (SBA). Também foi avaliado os } \\
\text { impactos dos cenários de } \\
\text { política de desmatamento na } \\
\text { agricultura da região. }\end{array}$ \\
\hline $\begin{array}{l}\text { ARTIGO } \\
\text { XII }\end{array}$ & $\begin{array}{l}\text { Population Growth } \\
\text { and Net Migration in } \\
\text { the Brazilian Legal } \\
\text { Amazon, 1970- 1996, } \\
\text { em WOOD e PORRO. }\end{array}$ & $\begin{array}{l}\text { Perz, 2002, } \\
\text { Estados } \\
\text { Unidos. }\end{array}$ & $\begin{array}{l}\text { O artigo baseou-se nos dados } \\
\text { do censo demográfico brasileiro } \\
\text { para mostrar como as } \\
\text { populações cresceram na } \\
\text { Amazônia entre } 1970 \text { e } 1996 \text {, o }\end{array}$ \\
\hline
\end{tabular}




\begin{tabular}{|c|c|c|c|}
\hline & & & $\begin{array}{l}\text { que levou ao desmatamento, } \\
\text { com ênfase em como } \\
\text { a migração contribuiu para esse } \\
\text { crescimento. Foi analisado onde } \\
\text { concentra o crescimento } \\
\text { populacional para a região em } \\
\text { geral, bem como para seus } \\
\text { componentes rurais e urbanos. }\end{array}$ \\
\hline $\begin{array}{l}\text { ARTIGO } \\
\text { XIII }\end{array}$ & $\begin{array}{l}\text { Estudo dos arbovirus } \\
\text { na Amazônia } \\
\text { Brasileira. }\end{array}$ & $\begin{array}{l}\text { Rodrigues, } \\
\text { 2004, Brasil. }\end{array}$ & $\begin{array}{l}\text { A pesquisa procurou rever os } \\
\text { aspectos ecoepidemiológicos } \\
\text { apresentados pelos vírus da } \\
\text { encefalite de St. Louis (SLE), } \\
\text { encefalites equinas Leste } \\
\text { (EEE), Oeste (WEE) e } \\
\text { Venezuelana [subtipos III, } \\
\text { Mucambo (MUC) e IV, Pixuna } \\
\text { (PIX)], decorrentes dos estudos } \\
\text { realizados em diversas áreas da } \\
\text { Região Amazônica brasileira, } \\
\text { especialmente ao longo das } \\
\text { rodovias e projetos de } \\
\text { desenvolvimento. }\end{array}$ \\
\hline $\begin{array}{l}\text { ARTIGO } \\
\text { XIV }\end{array}$ & $\begin{array}{l}\text { A pobreza e a riqueza } \\
\text { na região amazônica e } \\
\text { a contribuição da } \\
\text { política de assistência } \\
\text { social: o estado do } \\
\text { amazonas em foco. }\end{array}$ & $\begin{array}{l}\text { Rolim, 2015, } \\
\text { Brasil. }\end{array}$ & $\begin{array}{l}\text { O artigo abordou as } \\
\text { contradições entre a pobreza e } \\
\text { a riqueza e a contribuição da } \\
\text { política de assistência social no } \\
\text { Estado do Amazonas. Mostrou } \\
\text { como resultado que a } \\
\text { atualmente Manaus, capital do } \\
\text { Estado convive com as }\end{array}$ \\
\hline
\end{tabular}




\begin{tabular}{|c|c|c|c|}
\hline & & & $\begin{array}{l}\text { contradições da nova ordem } \\
\text { capitalista onde visualiza-se a } \\
\text { justaposição entre a riqueza e a } \\
\text { pobreza. }\end{array}$ \\
\hline $\begin{array}{l}\text { ARTIGO } \\
X V\end{array}$ & $\begin{array}{l}\text { Modelo de } \\
\text { organização de } \\
\text { indicadores para } \\
\text { operacionalização dos } \\
\text { determinantes } \\
\text { socioambientais da } \\
\text { saúde. }\end{array}$ & $\begin{array}{l}\text { Sobral e } \\
\text { Freitas, 2010, } \\
\text { Brasil. }\end{array}$ & $\begin{array}{l}\text { Verificou-se no estudo as } \\
\text { determinantes sociais e suas } \\
\text { relações com o processo } \\
\text { saúde-doença entre diferentes } \\
\text { grupos populacionais e sua } \\
\text { grande relevância para a Saúde } \\
\text { Pública e como vêm ganhando } \\
\text { cada vez mais destaque. Nesse } \\
\text { processo, modelos teórico- } \\
\text { conceituais vêm sendo } \\
\text { adotados para explicar como os } \\
\text { determinantes sociais geram } \\
\text { iniquidades em saúde. }\end{array}$ \\
\hline $\begin{array}{l}\text { ARTIGO } \\
X V I\end{array}$ & $\begin{array}{l}\text { Saúde ambiental e } \\
\text { desenvolvimento na } \\
\text { Amazônia legal: } \\
\text { indicadores } \\
\text { socioeconômicos, } \\
\text { ambientais } \\
\text { sanitários, desafios e } \\
\text { perspectivas. }\end{array}$ & $\begin{array}{l}\text { Viana et al., } \\
\text { 2016, Brasil. }\end{array}$ & $\begin{array}{l}\text { O artigo procurou discutir os } \\
\text { processos de determinação } \\
\text { socioambiental nos estados que } \\
\text { compõem a Amazônia Legal, } \\
\text { com base na análise de } \\
\text { indicadores socioeconômicos, } \\
\text { ambientais e sanitários. }\end{array}$ \\
\hline $\begin{array}{l}\text { ARTIGO } \\
\text { XVII }\end{array}$ & $\begin{array}{l}\text { Saúde, ambiente e } \\
\text { desenvolvimento } \\
\text { econômico na } \\
\text { Amazônia. }\end{array}$ & $\begin{array}{l}\text { Vincentin e } \\
\text { Minayo, } \\
\text { 2003, Brasil. }\end{array}$ & $\begin{array}{l}\text { O estudo analisou o processo } \\
\text { de transformação do padrão } \\
\text { epidemiológico de uma } \\
\begin{array}{l}\text { população } \\
\text { constituída para trabalhar no }\end{array}\end{array}$ \\
\hline
\end{tabular}




\begin{tabular}{|c|c|c|c|}
\hline & & & $\begin{array}{l}\text { desenvolvimento da Mineração } \\
\text { Rio do Norte S.A. (MRN), no } \\
\text { município de Oriximiná (PA), na } \\
\text { localidade de Porto Trombetas. } \\
\text { A determinação do processo } \\
\text { saúde-doença se desenvolveu } \\
\text { segundo as condições } \\
\text { particulares de reprodução } \\
\text { social do empreendimento, } \\
\text { bastante distintas em relação às } \\
\text { das populações vinculadas ao } \\
\text { desenvolvimento } \\
\text { socioeconômico tradicional da } \\
\text { região. }\end{array}$ \\
\hline $\begin{array}{l}\text { ARTIGO } \\
\text { XVIII }\end{array}$ & $\begin{array}{l}\text { Deforestation, Hunting } \\
\text { and the Ecology of } \\
\text { Microbial Emergence }\end{array}$ & $\begin{array}{l}\text { Wolfe, 2000, } \\
\text { Estados } \\
\text { Unidos. }\end{array}$ & $\begin{array}{l}\text { O estudo buscou compreender } \\
\text { como novos micróbios entram } \\
\text { na população humana, qual a } \\
\text { frequência com que os } \\
\text { micróbios emergem de acordo } \\
\text { com a determinação dada pela } \\
\text { diversidade de micróbios } \\
\text { presentes no ambiente, com } \\
\text { também, o nível de contato } \\
\text { entre um hospedeiro potencial a } \\
\text { diversidade microbiana e a } \\
\text { susceptibilidade do novo } \\
\text { hospedeiro à infecção }\end{array}$ \\
\hline
\end{tabular}

Fonte: próprios autores. 
Dentre os artigos escolhidos, a grande maioria dos estudos mostrou que os fatores ambientais e sociológicos que contribuem para o surgimento de doenças na região Amazônica desde o ano de 1970, como mostra o artigo "Chagas disease and globalization of the Amazon" do autor Briceño-Léon (2007), fazendo esse apanhado histórico. Essa mudança na epidemiologia das doenças na região amazônica pode ser explicada pelas mudanças ambientais e sociais nos últimos 30 anos, como explica o autor.

Os artigos autores Browder e Godfrey (2017), Browder e Godfrey (2017), Cardoso (2015), Carrapato et al. (2017), Confalonieri (2000), Confalonieri (2005), Medeiros (2014), Nobre (2004), Perz (2002), Sobral e Freitas (2010) e Viana et al. (2016) em suas pesquisas publicadas, em síntese, demostraram a relação dos fatores determinantes sociais e ambientais e sua intrínseca ligação com o processo saúdedoença de diferentes populações, sua significativa relevância para a saúde pública e como eles se tornaram mais proeminentes. Nesse processo de anos de histórias que a Amazônia vem enfrentando com mudanças sociais e de espaço físico e territorial, e como consequências o agravo de doenças concentradas nessa região.

\section{REVISÃO DE LITERATURA E DISCUSSÃO}

\subsection{ASPECTOS REGIONAIS}

Um fenômeno muito importante no meio ambiente amazônico é a interação entre a atmosfera e as florestas, que desempenham um papel importante na produção de chuvas na região. O clima é geralmente quente e úmido e a temperatura não muda muito, sendo um importante regulador dos processos biológicos, principalmente os relacionados às doenças infecciosas (NOBRE, 2004).

Outro aspecto biofísico relacionado envolve a biodiversidade, especialmente a diversidade animal. Alguns processos de infecção focal nesta área, especialmente os processos de infecção viral, dependem de insetos sugadores de sangue (vetores) para a transmissão (arbovírus). Quanto maior a diversidade de espécies animais 
(vertebrados e invertebrados) em uma determinada área, maior o risco de um novo processo de infecção Wolfe (2000). Para exemplificar esse ponto, cerca de 196 arbovírus foram identificados na Amazônia, 32 dos quais podem infectar humanos (RODRIGUES, 2004).

Nobre (2004) ressalta que em relação à sociedade amazônica, os seguintes aspectos demográficos importantes podem ser destacados:

I. Baixa densidade populacional regional (aproximadamente 20 milhões de habitantes em uma área de 3,5 milhões de quilômetros quadrados) (INPE, 2013; IBGE, 2013);

II. a alta taxa de crescimento proporcionada pela imigração nos últimos 30 anos. Também há uma forte migração inter-regional (PERZ, 2002);

III. as cidades são altamente concentradas, principalmente nas capitais. Aproximadamente $70 \%$ da população amazônica vive em cidades grandes e pequenas. O surgimento rápido, espontâneo e desordenado de muitos desses pequenos assentamentos urbanos sem a necessária de infraestrutura de saneamento é característico (BROWDER e GODFREY, 2017);

IV. é grande o número de populações tradicionais (índios, ribeirinhos, seringueiros, etc.) que vivem do extrativismo e da pequena agricultura (INPE, 2013; IBGE, 2013).

Outra característica regional importante diz respeito às práticas de uso da terra e seus impactos ambientais e sociais. Algumas dessas práticas produzem mudanças ambientais que apresentam riscos à saúde. É o caso da poluição por mercúrio nas minas; devido à falta de infraestrutura de saneamento nas áreas urbanas, a água é contaminada por microrganismos; a fumaça das queimadas após o desmatamento causa problemas respiratórios; mudanças locais no ciclo hidrológico que produzem criadouros do mosquito, para enumerar apenas alguns efeitos mais diretos (CONFALONIERI, 2000). 
Também deve ser lembrado que os conflitos sociais, por exemplo, a posse da terra leva à violência e conflitos culturais, e o impacto drástico de povos indígenas isolados e a introdução de agentes microbianos até então desconhecidos por essas comunidades, proporcionando o surgimento de novas doenças e elevando o número de casos das existentes na região (RODRIGUES, 2004).

O pano de fundo comum desses eventos é que as políticas de desenvolvimento e uso de recursos ignoram o potencial regional, esquecendo da resiliência ambiental e da sustentabilidade ecológica da Amazônia, não conduzem à cultura tradicional ou à distribuição de renda e não se preocupam com os riscos à saúde (CONFALONIERI, 2000).

$\mathrm{Na}$ prática, isso está acontecendo tanto por iniciativa do governo, por meio da implantação de grandes projetos de infraestrutura (rodovias, hidrelétricas etc.) e da indústria (mineração comercial), incentivando a pecuária (e o desmatamento), como também por meio de atividades extrativistas espontâneas, como o garimpo, a pesca, a extração de madeira e outras (BRICEÑO-LEÓN, 2007; VICENTIN e MINAYO, 2003; FREITAS e GIATTI, 2009).

\subsection{INDICADORES SOCIOAMBIENTAIS}

No espaço que circunda as partes sul e leste da Amazônia (estados de Rondônia, Mato Grosso, Tocantins, Maranhão e Pará), focos de queimadas, desmatamento acumulado e construção de rodovias, além de áreas de cultivo e intensificação do consumo de agrotóxicos se intensificaram nos últimos anos (INPE, 2013; IBGE, 2013).

Esses recursos foram chamados por Nobre (2004) de "arco de fogo". Em relação ao consumo de agrotóxicos, os índices alcançados com essas substâncias na região foram expressivos, representando $18 \%$ do total nacional. Segundo os dados publicados em 2009 pelo Instituto Brasileiro de Geografia e Estatística (IBGE), o 
estado de Mato Grosso atingiu a maior taxa nacional de uso de agrotóxicos por hectare de área cultivada na Amazônia Legal (IBGE, 2013).

De acordo com os indicadores examinados, os dados de aumento de terras cultiváveis e pastagens sobre áreas naturais e desmatamento cumulativo na Amazônia atingiram as maiores taxas no mesmo 'arco de fogo', com nítida convergência entre a expansão da agricultura extensiva e desmatamento junto com a ocorrência de queimadas e uso de agrotóxicos (CARDOSO, 2015).

Seguindo o raciocínio e salvamento de Confalonieri (2005), é possível mostrar o quanto as sociedades amazônicas vivenciam dificuldades no acesso à saúde e, consequentemente, falta de assistência e doenças. O autor chama a atenção para fatores como: baixa densidade demográfica regional, crescimento significativo da migração, incluindo migrações inter-regionais, alta concentração de cidades, principalmente nas capitais, com carência de infraestrutura sanitária e existência de grande contingente de populações tradicionais, prejudica os determinantes sociais na Amazônia, causando graves problemas de saúde.

Para os autores Medeiros et al. (2014) a situação das condições de trabalho nas áreas de paisagem natural e antrópica da Amazônia também foi discutida. Isso porque as condições e o ambiente de trabalho são determinantes de saúde-doenças ocupacionais e são classificados como doenças não transmissíveis. Portanto a saúde do trabalhador é conceituada como:

\footnotetext{
Um campo de saúde pública que tem como objeto de estudo e intervenção as relações produção-consumo e o processo saúdedoença. Neste campo, o trabalho é considerado como eixo organizador da vida social, espaço de dominação e resistência dos trabalhadores e determinantes das condições de vida e saúde das pessoas (BRASIL, 2018, p. 136).
}

O trabalho é um importante determinante da vida e da saúde das pessoas. Sabendo que existem muitas atividades, relações e condições de serviço diferenciadas na região amazônica, é importante que os profissionais de saúde promovam, previnam 
e diagnostiquem doenças relacionadas as tarefas que são realizadas na região da Amazônia (CARDOSO, 2015).

Nessas atividades profissionais muito específicas da Amazônia, que são raros em outras partes do Brasil, podem-se citar: extrativismo vegetal - profissão, que inclui, entre outras extrativista de açaí, compactador de borracha, coletor de castanha-dopará, Pilotos de barcos de transporte de passageiros, garimpeiros, pescadores e muitos mais. Percebe-se também que as relações de trabalho altamente degradantes, que em muitos lugares podem ser consideradas análogas à escravidão, são bastante evidentes na região devido à dificuldade de controlar a grande expansão de terras na Amazônia.

Por se tratar de uma área rica em minério os garimpeiros se instalam nesta região e em áreas protegidas onde a mineração é proibida. Em decorrência de adentrarem áreas de matas tanto os garimpeiros como os extratores de castanha-do-pará e seringueiros são afetados por doenças bacterianas transmitidas por vetores ou não transmissíveis e por protozoários que existem na floresta.

Entre eles, pode-se citar a doença de Chagas, malária, leishmaniose e muitas doenças virais na região. Portanto, dado o grande número desses profissionais e os riscos que enfrentam, o sistema de saúde deve direcionar ações para que as doenças direta ou indiretamente relacionadas ao trabalho não se tornem um fator de aumento de morbimortalidade na região amazônica (CARDOSO, 2015).

É importante destacar que o debate sobre o trabalho da Amazônia e sua abrangência é muito rico, pois mostra ainda que a Amazônia é um lugar que ainda se recente de pesquisas e políticas públicas de saúde específicas sobre as condições de vida, saúde-doença e trabalho na região (BENSABATH e SOARES, 2016).

RC: 102839

Disponível em: https://www.nucleodoconhecimento.com.br/saude/surgimento-dedoencas 


\subsection{INDICADORES EPIDEMIOLÓGICO REGIONAL}

Em relação aos indicadores epidemiológicos regionais, existem algumas diferenças importantes entre a região amazônica e o restante do país. Em 1996, a taxa de internações por doenças infecciosas e parasitárias era muito elevada $(12,7 \%)$, muito superior à média nacional (8,3\%). Embora a incidência dessas lesões tenha diminuído na Amazônia, a taxa de mortalidade por essas doenças não tem sido a mesma (SUDAM, 2000).

Essa região abriga a grande maioria dos casos de malária no país (98\%), aproximadamente $35 \%$ dos casos de hanseníase em 2016, e a segunda maior incidência de tuberculose entre todas as regiões do país. É também uma área altamente endêmica de hepatites virais com surtos frequentes, especialmente na Amazônia Ocidental (BENSABATH e SOARES, 2016).

Destaca-se que devido as condições geográficas da região, bem como, o processo de urbanização e ausência de saneamento básico contribuíram para o processo de doenças que reemergiram na Amazônia, como cólera em 1991 e dengue em meados da década de 1990, além destas, outras doenças também causam grandes números de óbitos na população da região como a malária, leishmaniose tegumentar americanas infecções parasitarias e principalmente a tuberculose (VIANA et al., 2016).

A literatura também revela a relação desproporcional entre melhoria da qualidade de vida e degradação ambiental, ou seja, o desenvolvimento avança de forma insustentável, e ressalta a importância de se considerar o custo das doenças causadas por fatores ambientais, que tem aumentado na região amazônica (MEDEIROS et al., 2014).

Carrapato; Correa e Garcia (2017) imediatamente vincularam qualidade de vida à saúde. Os autores enfatizam que, além dos modelos biomédicos, existem alguns fatores decisivos que afetaram ou afetarão de forma decisiva a saúde pessoal.

RC: 102839

Disponível em: https://www.nucleodoconhecimento.com.br/saude/surgimento-dedoencas 
Portanto, esses determinantes atualmente têm um impacto maior na saúde do que aqueles atualmente cobertos pela medicina. Enfatizaram a existência de três determinantes: meio ambiente, economia e sociedade, para eles os determinantes sociais são os grandes responsáveis pela injustiça de acesso aos cuidados de saúde.

\section{CONCLUSÃO}

Com base na questão norteadora do estudo, é possível inferir que os principais fatores ambientais que contribuem para o surgimento de doenças na região amazônica são o desmatamento, queimadas, poluição dos rios, processo de urbanização e agronegócio, desta forma conclui-se que a discussão sobre o estudo finalmente identificou algumas questões que são responsáveis pelo número de doenças na Amazônia, onde deve-se, por exemplo, considerar os aspectos geográficos, étnicos, culturais e políticos da saúde na região amazônica. Denota-se que, faltam políticas públicas que atendam a demanda de saúde-doenças relacionadas aos indicadores socioambientais da região, bem como, a necessidade de serem realizados mais estudos e pesquisas com 0 intuito de conhecer as adversidades enfrentadas por essas populações.

Ressalta-se também que os principais fatores ambientais que contribuem para o surgimento de doenças na região amazônica são o desmatamento, queimadas, poluição dos rios, processo de urbanização e agronegócio, ou seja, todos a partir da ação do homem

Contudo, o estudo mostra ainda que sob a ótica dos indicadores ambientais de saúde e doença, o espaço amazônico formado pela interação do sistema socioecológico apresenta características distintas de outras partes do país. Essa diferença é causada pelo fundamento ecológico natural e suas formas de ocupação e desenvolvimento. 


\section{REFERÊNCIAS}

BENSABATH, G. e SOARES, M. C. P. A evolução do conhecimento sobre hepatites virais na região Amazônica: da epidemiologia e etiologia à prevenção. Rev. Soc. Bras. Med. Trop., 37(supl. II):14-36, 2016.

BRASIL. Ministério da Saúde. Secretaria de Atenção à Saúde. Secretaria de Vigilância em Saúde. Saúde do trabalhador e da trabalhadora [recurso eletrônico]. Cadernos de Atenção Básica, n. 41 - Brasília: Ministério da Saúde, 2018. 136 p.: il.

BRICEÑO-LEÓN, R. Chagas disease and globalization of the Amazon. Cadernos de Saúde Pública, Rio de Janeiro, v. 23, n. 53, p. 33-40, 2007. Suplemento 1.

BROWDER, J. O. e GODFREY, B. J. Rainforest Cities. Urbanization, Development and Colonization of the Brazilian Amazon. Columbia University Press, New York, 2017, 429 pp.

CAÑETE, T. M. R..; RAVENA-CAÑETE, V. Populações Tradicionais Amazônicas: revisando conceitos. In: V Encontro Nacional da Associação Nacional de PósGraduação e Pesquisa em Ambiente e Sociedade, 2010, Florianópolis Anais, V Encontro Nacional da Associação Nacional de Pós-Graduação e Pesquisa em Ambiente e Sociedade, 2010.

CARDOSO, A. C. M. O trabalho como determinante do processo saúde-doença. Tempo soc., São Paulo, v. 27, n. 1, p. 73-93, junho de 2015.

CARRAPATO, P.; CORREIA, P.; GARCIA, B. Determinante da saúde no Brasil: a procura da equidade na saúde. Saúde soc., São Paulo, v. 26, n. 3, p. 676- 689, Sept. 2017.

CONFALONIERI, U. E. C. (org.). The Health of Indigenous Peoples in the Brazilian Amazon. Background paper for the World Bank. Royal Tropical Institute, Amsterdam, 2000, 218 pp. 
CONFALONIERI, U. E. C. Saúde na Amazônia: um modelo conceitual para a análise de paisagens e doenças. Estud. av., São Paulo, v. 19, n. 53, p. 221-236, Apr. 2005.

FREITAS, C. M.; GIATTI, L. L. Indicadores de sustentabilidade ambiental e de saúde na Amazônia Legal. Cadernos de Saúde Pública, Rio de Janeiro, v. 25, n. 6 , p. 1251-1266, 2009.

IBGE - INSTITUTO BRASILEIRO DE GEOGRAFIA E ESTATÍSTICA. Contas nacionais: 2011. Rio de Janeiro, RJ, 2013.

INPE - Instituto Nacional De Pesquisas Espaciais. Monitoramento da floresta amazônica brasileira por satélite: 1988/2011. 2013.

MEDEIROS, M. S. de et al. Custo das doenças atribuíveis a fatores ambientais na cidade de Manaus, Amazonas, Brasil. Ciênc. Saúde coletiva [online]. 2014, vol.19, n.2, pp.599-608. 2014.

NOBRE, C. A. Recent Progress in Modeling Biome-Climate Interactions in Amazônia. Resumo 19.2. Anais III Conf. Cient.do LBA, 27-29 de julho, 2004. Brasília, DF, Cd-Rom.

PERZ, S. Population Growth and Net Migration in the Brazilian Legal Amazon, 1970- 1996, em WOOD e PORRO. Deforestation and Land Use in the Amazon. Gainesville, University Press of Florida, 2002, pp. 95-106.

RODRIGUES, S. G. Estudo dos arbovirus na Amazônia Brasileira. Em: Resumos do III Simpósio Internacional sobre Arbovirus nos Trópicos e Febres Hemorrágicas, Belém, Pará, 30/11 - 3/12, 2004. Instituto Evandro Chagas, 2004.

ROLIM, D. C. A pobreza e a riqueza na região amazônica e a contribuição da política de assistência social: o estado do amazonas em foco. VII Jornada 
Internacional de Políticas Públicas. Programa de Pós-graduação em políticas públicas. Universidade Federal do Maranhão, 2015.

SOBRAL, A.; FREITAS, C. M. Modelo de organização de indicadores para operacionalização dos determinantes socioambientais da saúde. Saúde e Sociedade, São Paulo, v. 19, n. 1, p. 35-47. 2010.

SUDAM. Diagnóstico e cenarização macrossocial da Amazônia legal: perfil da saúde na Amazônia legal e o contexto brasileiro. Belém, Pnud, 2000, 54 p.

VIANA, Rosana Lima; FREITAS, Carlos Machado de; GIATTI, Leandro Luiz. Saúde ambiental e desenvolvimento na Amazônia legal: indicadores socioeconômicos, ambientais e sanitários, desafios e perspectivas. Saúde e Sociedade, v. 25, p. 233246, 2016.

VICENTIN, G.; MINAYO, C. G. Saúde, ambiente e desenvolvimento econômico na Amazônia. Ciência e Saúde Coletiva, Rio de Janeiro, v. 8, n. 4, p. 1069- 1085, 2003.

WOLFE, N. Deforestation, Hunting and the Ecology of Microbial Emergence. Global Change \& Hum. Health, 1(1):10-25, 2000.

Enviado: Dezembro, 2021.

Aprovado: Dezembro, 2021 